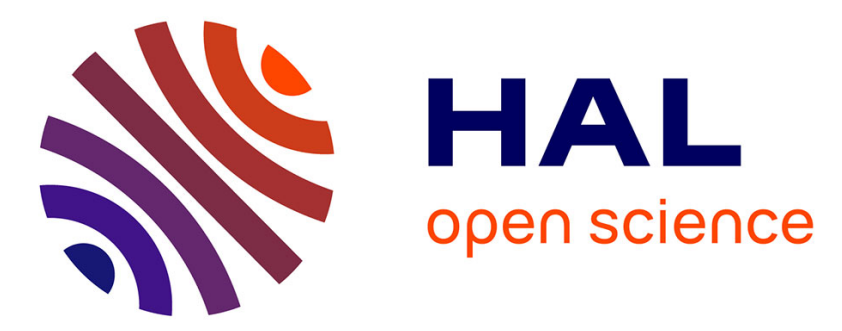

\title{
Age, sex, mating status, but not social isolation interact to shape basal immunity in a group-living insect
}

Fanny Vogelweith, Susanne Foitzik, Joël Meunier

\section{To cite this version:}

Fanny Vogelweith, Susanne Foitzik, Joël Meunier. Age, sex, mating status, but not social isolation interact to shape basal immunity in a group-living insect. Journal of Insect Physiology, 2017, 103 (11), pp.64-70. 10.1016/j.jinsphys.2017.10.007 . hal-02117957

\section{HAL Id: hal-02117957 \\ https://hal-univ-tours.archives-ouvertes.fr/hal-02117957}

Submitted on 20 May 2020

HAL is a multi-disciplinary open access archive for the deposit and dissemination of scientific research documents, whether they are published or not. The documents may come from teaching and research institutions in France or abroad, or from public or private research centers.
L'archive ouverte pluridisciplinaire HAL, est destinée au dépôt et à la diffusion de documents scientifiques de niveau recherche, publiés ou non, émanant des établissements d'enseignement et de recherche français ou étrangers, des laboratoires publics ou privés. 
Age, sex, mating status, but not social isolation interact to shape basal immunity in a group-living insect

Fanny Vogelweith ${ }^{1} \#$, Susanne Foitzik ${ }^{1}$, Joël Meunier ${ }^{1,2}$

${ }^{1}$ Institute of Organismic and Molecular Evolution, Behavioral Ecology and Social Evolution Group, Johannes-Gutenberg University of Mainz, Mainz, Germany

${ }^{2}$ Institut de Recherche sur la Biologie de l'Insecte, UMR CNRS 7261, University of Tours, Tours, France

\# Corresponding author: F. Vogelweith (fanny.vogelweith@gmail.com) 


\begin{abstract}
Immunity is a crucial but costly trait. Individuals should therefore adjust their investment into immunity to their condition and infection risks, which are often determined by their age, sex, mating status and social environment. However, whether and how these four key factors can interact to shape basal immunity remains poorly understood. Here, we tested the simultaneous effects of these factors on hemocyte concentration and phenoloxidase activity in adults of the European earwig. We found that hemocyte concentration increased with age, and that this increase was stronger in males. We also found an age-dependent increase in phenoloxidase activity in males and virgin females, but not in mated females. However, the two immune parameters were independent of social isolation. Overall, our results reveal that a complex interplay between age, sex and mating status determines basal immunity and stress the importance of interactions in our understanding of immune investment.
\end{abstract}

Key words: Aging, insect immunity, mating, Forficula auricularia, sex, social isolation. 


\section{Introduction}

Survival and reproduction often depend on the ability of an organism to fight against pathogens and parasites (Schmid-Hempel, 2005). As a consequence, vertebrates and invertebrates alike developed a strong and efficient immune system (Schmid-Hempel, 2005). However, investing into immune functions is costly (Armitage et al., 2003). Hosts are thus expected to adjust their immune investment to internal and external parameters, such as their own condition (e.g. age and sex (Rolff, 2002)), their potential access to group protection (e.g. through social immunity (Cremer et al., 2007)) and their risks of pathogen/parasite exposure (Schmid-Hempel, 2005). Better understanding the evolution of immune defenses therefore requires shedding light on the parameters that can independently or interactively promote the investment of an individual into its immune functions.

Aging, mating status and sex are three parameters often assumed to shape the immune investment of an individual, but for which the nature and direction of the effects can be contrasting across species and taxa. Although aging is traditionally known to decrease the efficiency of the immune system in many vertebrate and invertebrate species (Mackenzie et al., 2011; Park et al., 2011; Selman et al., 2012; Stanley, 2012), recent works show that it may also improve immune capabilities. For instance in insects, aging has been found to increase phenoloxidase (PO) activity - a key enzyme involved in insect immunity - in the leaf-cutting ant Acromyrmex octospinosus (Armitage and Boomsma, 2010) and the flour beetle Tribolium castaneum (Khan et al., 2016). Similarly, mating is an energetically costly process which is also a source of disease transmission (Lawniczak et al., 2007; McKean and Nunney, 2001; Rolff and Siva-Jothy, 2002), so that investments in mating and immunity are generally expected to trade-off in nature (McKean and Nunney, 2001; Rolff and Siva-Jothy, 2002). Whereas the occurrence of such a trade-off has been reported across many species and taxa (e.g. in the tree lizards Urosaurus ornatus (French et al., 2007) and in D. melanogaster 
(McKean and Nunney, 2001)), this process is not ubiquitous in nature and is absent in some species, such as in the Brandt's vole Lasiopodomys brandtii (Xu et al., 2012) and the mealworm beetle Tenebrio molitor (Armitage et al., 2003). Finally, females are often expected to invest more strongly into immune functions compared to males (Rolff, 2002). This is because longevity is traditionally thought to be a major determinant of female but not of male fitness. Females should favor post-mating survival to ensure offspring production and survival (in case of maternal care), whereas males should favor mating success over postreproduction survival (in absence of paternal care, as found in most species (Rolff, 2002; Trivers, 1972)). This higher level of immunity in females compared to males has been reported in many species such as the scorpion fly Panorpa vulgaris (Kurtz et al., 2000) and the yellow dung fly Scathophaga stercoraria (Schwarzenbach et al., 2005). However, sex differences in immunity can also go in the opposite direction, such as with males exhibiting higher immunity in the cabbage white butterfly Pieris rapae (Stoehr, 2007) and the striped ground cricket Allonemobius socius (Fedorka et al., 2004).

In addition to these parameters, the presence or absence of conspecifics may also have contrasting effects on immune investment. Living with one or more conspecifics typically entails an increased risk of pathogen exposure and infection (Cremer et al., 2007; Wilson et al., 2003). To limit this risk, the density-dependent prophylaxis (DDP) hypothesis (Wilson and Cotter, 2008; Wilson and Reeson, 1998) predicts that group-living animals should prophylactically increase their immunity when the density of conspecifics increases in the environment. This has been supported in different bird species, where immunocompetence was found to be positively associated with nesting colony size (Møller et al., 2001), as well as in the locust Locusta migratoria, where resistance against the entomopathogenic fungus Metarhizium anisopliae increases with density (Wilson et al., 2002). On the other hand, living with conspecifics can also give access to collective defense against pathogens, a phenomenon 
called social immunity (Cremer et al., 2007; Meunier, 2015), which increases resistance against disease (Wilson-Rich et al., 2009) and therefore allows a reduced investment into personal immune functions (Cotter and Kilner, 2010; Meunier, 2015; Wilson and Cotter, 2008). This trade-off between social and personal immunity has been reported in the burying beetle Nicrophorus vespilloides, in which enforcing an increased investment into personal immunity temporarily reduced investment into social immunity (Cotter et al., 2013).

Whereas aging, mating status, sex and the presence/absence of a social environment individually shape the immune functions of many species across taxa, the interactive effects of these factors remain poorly investigated. This is surprising because many of these factors are likely to interact to shape immune investment. For instance, the importance of finding a mating partner increases over time in virgins, so that old virgin females might benefit from favoring investment into reproduction over immunity, whereas old mated females should favour investment into immunity over reproduction in order to survive long enough to be able to provide care to their offspring. Similarly, males from many species are aggressive against each other, so that earwig males could favor investment into fighting abilities when living with other males, and into other traits, such as immunity, when living in isolation.

In this study, we simultaneously investigated the independent and interactive effects of aging, sex, mating status and social isolation on immunity in adults of the European earwig $F$. auricularia. In this insect species, males and females live in uni- or multi-sex groups for several months during summer (Lamb and Wellington, 1975; Sandrin et al., 2015). These groups generally include two to several dozens of individuals. Group members interact both through aggressive and apparently cooperative behaviors (Weiss et al., 2014). In autumn, females leave their group and lay eggs in isolation. Earwig males typically die in winter (lifespan $=8$ months), whereas earwig females survive for 18 months during which they 
provide extensive forms of care to their first- and second-clutch of eggs and juveniles (Koch and Meunier, 2014; Meunier et al., 2012; Ratz et al., 2016).

Here, we conducted a $3 \times 3$ full-factorial experiment in which male and female earwigs were mated or virgin and maintained in pairs or in isolation during their entire reproductive period (4 months, Figure 1). We measured the investment of males and females into immunity both before and after this period, as well as recorded the survival of each of these individuals over the same timeframe. In insects, the efficiency of the immune system mainly relies on the coordinate action of the hemocytes and the phenoloxidase (PO) enzymatic cascade (Siva-Jothy et al., 2005). Hemocytes are immune cells that circulate in the hemolymph and are involved in recognition and encapsulation of pathogens (Lavine and Strand, 2002). Conversely, phenoloxidase mostly mediates the melanization of foreign objects and operates through the activation of prophenoloxidase, its inactive precursor typically stored in the hemolymph and the hemocytes (Cerenius and Söderhäll, 2004). In this study, our immunity measures were the basal hemocyte concentration and the phenoloxidase/ prophenoloxidase (total-PO) activity. The latter was defined as the sum of phenoloxidase and prophenoloxidase activities, and therefore reflects the immunocompetence of an individual in terms of both already activated and the potentially to be activated phenoloxidase enzymatic cascade.

\section{Material and methods}

\subsection{Experimental design}

The tested individuals came from a first laboratory born generation of $F$. auricularia. These individuals were the descendants of males and females field-caught in July-August 2015 in Mainz, Germany $\left(49^{\circ} 58^{\prime} 20.5^{\prime \prime} \mathrm{N} 8^{\circ} 11^{\prime} 42.3^{\prime \prime} \mathrm{E}\right)$ and then reared under standard laboratory conditions (see details in (Vogelweith et al., 2017)). 
We measured the basal immunity of 149 males and 151 females coming from 128 different clutches both seven days after their emergence as adults (young adults) and four months later (old adults). In between these two measurements, each individual was set-up in one of four treatments (Figure 1). They were either (1) paired with an individual of the other sex ( $=62$ individuals; treatment paired + mated), (2) paired with an individual of the other sex for only 10 days - allowing mating - and then maintained in isolation $(\mathrm{n}=56$, isolated + mated), (3) paired with an individual of the same sex ( $n=60$ and 62 for males and females, respectively; paired + virgin) or (4) immediately isolated $(n=30$ and 30 for males and females, respectively; isolated + virgin). We also recorded the survival of each individual twice a week during the course of the experiment to ensure that the observed effects on immunity are not a by-product of an unintentional experimental selection against the weakest or strongest individuals.

Once allocated to their treatment, adults were maintained under standard laboratory conditions (18:20 ${ }^{\circ} \mathrm{C} 12: 12 \mathrm{~h}$ Dark:Light) and provided with an ad libitum amount of standard food, renewed twice a week (see food composition in (Kramer et al., 2015)). After the last immune measurement, the eye distance of each adult (a proxy for body size (Kramer and Meunier, 2015; Thesing et al., 2015) was measured to the nearest $0.001 \mathrm{~mm}$ on photographs taken under a binocular scope (Leica, MZ 12.5; magnification $\times 0.8$ ) and analyzed using the Leica Application Suite 4.5 software (Leica Microsystems, Wetzlar, Germany). Note that each individual was marked just after the $1^{\text {st }}$ immune measurement and before the treatment allocation by cutting two millimeters of one of its two wing covers (either right or left, random choice) and that the paired individuals were always unrelated. During the experiment, nine females laid eggs and were consequently removed from the analyses: three females grouped + mated, two females isolated + mated, three females grouped + virgin and one female isolated + virgin. To confirm that virgin females can only produce unfertilized and 
thus non-viable eggs, all eggs were kept until the expected time of hatching. In line with our prediction, all eggs laid by virgin females were covered with mold after a few weeks, whereas the ones produced by mated females hatched into juveniles.

\subsection{Measurement of the two immune parameters}

We measured two key immune parameters on adult males and females: the total-PO activity and the concentration of circulating hemocytes. We measured two key immune parameters in adult males and females: the total-PO activity and the concentration of circulating hemocytes. To this end, all individuals were first anesthetized with $\mathrm{CO}_{2}$ for 20 seconds. Hemolymph extractions were then performed using a thin needle by piercing the cuticle between the $2^{\text {nd }}$ and $3^{\text {rd }}$ segment on the dorsal side of the abdomen. The two extractions were performed four months apart, giving the earwigs ample time to recover. We extracted an average of $1.63 \mu 1$ $(\min =0.5 \mu \mathrm{l} ; \max =2.2 \mu \mathrm{l} ;$ median $=1.9 \mu \mathrm{l})$ of hemolymph per adult using a glass-capillary. These extracts were immediately diluted in $25 \mu \mathrm{l}$ of cold sodium cacodylate $/ \mathrm{CaCl}_{2}$ buffer ( $0.01 \mathrm{M}$ sodium cacodylate, $0.005 \mathrm{M} \mathrm{CaCl} 2 ; \mathrm{pH}$ 6.5) to measure the two immune parameters. The concentration of hemocytes was measured immediately after hemolymph extraction, using $10 \mu \mathrm{l}$ of the diluted hemolymph of each male and female. This counting was done using a Neubauer Improved Haemocytometer and a microscope (magnification x 400), as described in Vogelweith et al. (2017).

Total-PO activity was spectrophotometrically measured using a standard protocol described in Vogelweith et al. (2017) and defined as the sum of phenoloxidase (PO) and prophenoloxidase (PPO) activities, therefore reflecting the immunocompetence of an individual in terms of both already activated and not- yet activated phenoloxidase enzymatic cascade. We first froze $6 \mu 1$ of diluted hemolymph from each male and female at $-20^{\circ} \mathrm{C}$. Each sample of frozen hemolymph was then thawed on ice and centrifuged for 5 minutes at $4{ }^{\circ} \mathrm{C}$ 
$(4000 \times \mathrm{g})$. Five $\mu \mathrm{l}$ of the resulting supernatant was then added to a microplate well containing $20 \mu \mathrm{l}$ of PBS and $140 \mu \mathrm{l}$ of chymotrypsin solution (Sigma C-7762, $0.07 \mathrm{mg} / \mathrm{ml}$ of distilled water). A volume of $20 \mu \mathrm{l}$ of L-dopa solution (Sigma D-9628; $4 \mathrm{mg} / \mathrm{ml}$ of distilled water) was then added to each well. The reaction was allowed to proceed for $167 \mathrm{~min}$ at $30^{\circ} \mathrm{C}$ in a microplate reader (Thermo scientific Multiskan ${ }^{\mathrm{TM}}$ FC Microplate Photometer). Enzyme activity was defined as the slope of the reaction curve during the linear phase of the reaction (Vmax value: change in absorbance units/min) and measured using the R-based program POCALC (Kohlmeier et al., 2015). Because the volume of extracted hemolymph and the resulting concentration of hemolymph slightly varied between individuals (see the range of extraction detailed above), we standardized the concentration of hemocytes and total-PO activity (immune parameters) per microliter of hemolymph using the following formula: I $\mathrm{x}$ $[(\mathrm{Vh}+\mathrm{Vb}) / \mathrm{Vh}] / \mathrm{Vm}$, in which $\mathrm{I}$ is the measured immune parameter, $\mathrm{Vh}$ is the volume of extracted hemolymph, $\mathrm{Vb}$ is the volume of buffer added, and $\mathrm{Vm}$ is the volume applied either

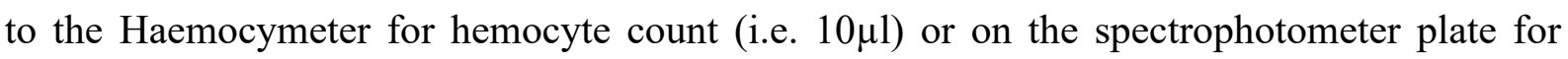

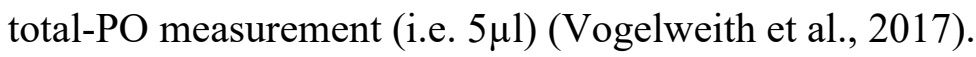

\subsection{Statistical analyses}

All the statistical analyses were conducted using the software R v3.4.0 loaded with the packages car, lme4, lsmeans and multcomp. We tested hemocyte concentration and total-PO activity using two General Linear Mixed Models (LMMs), in which the age (young or old adults), eye distance, mating status (mated or virgin), sex (female or male) and social isolation (isolated or paired) were entered as explanatory categorical factors. As haemolymph was extracted twice from each individual during the experiment, some individuals were maintained in the same group, or originated from the same clutch, we entered individual ID, Petri dish ID and clutch ID as random factors in these statistical models. Note that in these 
models, the effects of mating status on immune functioning should be illustrated by a significant interaction between mating status and age, and not by a significant main effect of mating status, as all the tested individuals were virgin at the "young" measurement (i.e. individuals from the mated treatment always include young virgin and old mated adults). The adult survival rate over time was tested using a generalized linear mixed-effects model (GLMM) with binomial error distribution. In this model, the mating status, sex and social isolation were entered as explanatory categorical factors, while the adult's ID, the Petri dish identification during the experiment and the original clutch of the tested individuals were entered as random effects. To fulfill homoscedasticity and Gaussian distribution, these models were computed using square root-transformed hemocyte concentration and log+0.00001transformed total-PO activity. All models first included interactions between all the explanatory factors and were then simplified stepwise by removing the non-significant interaction terms (all P-values $>0.05$ ), but not the interaction between mating status and age (see above). Note that to better understand the triple interaction that shaped total-PO activity (see results), we split the data set per sex and re-run the same model (without sex as an explanatory factor) in each data set.

\section{Results}

Contrasting interactions between age, mating status and sex shaped our two measurements of earwig immunity. On one hand, hemocyte concentration increased with age, and this increase was stronger in males than in females (interaction between age and sex in Table 1a; Figure 2; post-hoc Tuckey HSD tests, Males: $\mathrm{p}<0.0001$, Females: $\mathrm{p}=0.002)$. Hemocyte concentration was, however, independent of mating status and social isolation (Table 1a). On the other hand, the level of total-PO activity reflected a triple interaction between age, mating status and sex (Table $1 b)$. This interaction revealed that total-PO activity increased with age in 
virgins, but not in mated females (Table 1d, Figure 3a), whereas this age-dependent increase was present in both mated and virgin males (Table 1c, Figure 3b). Total-PO activity was overall independent of social isolation (Table 1b, c, d).

The average survival of earwigs during the reproductive period was $86.72 \%$. This rate was independent of mating status (Figure 4a; Wald $\chi^{2}=1.85 ; \mathrm{p}=0.173$ ), sex (Figure 4b; Wald $\chi^{2}=0.70 ; p=0.401$ ), social isolation (Figure 4c; Wald $\chi^{2}=3.69 ; p=0.055$ ) and of any interaction among these three factors (all $\mathrm{p}>0.07$ ).

\section{Discussion}

Although age, sex, mating status and social isolation are often considered key determinants of immunity in animals, whether and how these effects interact remains poorly explored. Based on a full-factorial experimental design, our results reveal that some of these components interact to shape immune functions in the European earwig $F$. auricularia. In particular, we showed that total-PO activity increases with age in all treatment groups, except for the mated females. Hemocyte concentration also overall increased with age, but was independent of mating status and sex. By contrast, social isolation had neither independent nor interactive effects on the two tested immune components. Hemocyte concentration also overall increased with age, but was independent of mating status and sex. By contrast, social isolation had neither independent nor interactive effects on the two tested immune components. Finally, we showed that the above results are unlikely to reflect an effect of the treatments on earwig survival, as survival rates were overall high and independent of mating status, sex and social isolation.

Contrary to the common assumption that the immune system deteriorates with age (Selman et al., 2012; Stanley, 2012), our results reveal that aging is associated with a general increase in the two immune parameters we have measured in males and females (with some 
limits, see below). Two hypotheses could explain our results. The first hypothesis is that individuals up-regulated their basal immune defense to limit an age-dependent decrease in individuals' capability to tolerate an infection (Khan et al., 2016; Ramsden et al., 2008). This hypothesis received support in the beetle $T$. castaneum, in which major components of the constitutive innate immune defense improve with age (Khan et al., 2016). The second hypothesis relies on the "winter immune-enhancement hypothesis" (Nelson and Demas, 1996), which predicts that individuals should enhance their immune functions, when harsh winter conditions are approaching. This prediction is well supported in vertebrates (Martin et al., 2008; Sinclair and Lochmiller, 2000), but remains poorly tested in invertebrates. In insects, one empirical support comes from a study conducted on the cricket Allonemobius socius (Fedorka et al., 2013b), which activate their PO cascade to darken their cuticle and thus improve their thermoregulation prior to encounter colder environments (Fedorka et al., 2013a, 2013b) - a darker cuticle is indeed often related to a thicker and less porous cuticle (Evison et al., 2017) and a better disease resistance (Dubovskiy et al., 2013). Our second immune measurement in earwigs is in line with this second hypothesis, as it was done at the end of the reproductive period, which is typically followed by relatively harsh winter conditions for males and females in nature. It is important to note that these winter conditions are crucial for the physiology of the earwigs, even when reared in the laboratory. If field winter conditions are not simulated, females are unable to lay eggs or else their eggs fail to develop into juveniles (J. Meunier, pers. comm.).

Somewhat surprisingly, mating inhibited the general age-dependent increase of immunity in terms of total-PO activity in females. This effect likely reflects the different functions of PO in insect physiology. In addition to its central role in the insect immune defense (Cerenius et al., 2008; González-Santoyo and Córdoba-Aguilar, 2012), PO is indeed known to be involved in egg production (González-Santoyo and Córdoba-Aguilar, 2012) and 
embryo development (Lacoue-Labarthe et al., 2009), as well as to exhibit costly cytotoxic effects when present in excess in an organism (Nappi and Christensen, 2005; Nappi and Ottaviani, 2000). The fact that old mated females limit the age-dependent increase of PO activity in their hemolymph could thus reveal that they partially shifted their PO contingent to other body parts, such as ovaries. This may both prevent its cytotoxic effects in individuals that need to survive relatively long after egg production (as compared to males), as well as favor the development of its fertilized eggs and embryo (as compared to virgin females). Further testing this hypothesis would require us to shed light on whether and how total-PO activities varies among different body parts of earwig males and females.

Contrary to total-PO activity, we found that hemocyte concentration was independent of mating status, but affected by the sex in adults. A prediction based on Rolff's theory (Rolff, 2002) is that females should exhibit higher immune investment compared to males. Our results, however, do not support this prediction in earwigs. We show that hemocyte concentration did not differ between young females and males, even if hemocyte concentration was lower in old females compared to old males. Somewhat surprisingly, these results contrast with the ones obtained in a previous study conducted on European earwigs, where we showed that hemocyte concentration was higher in ten-day old females compared to ten-day old males (Vogelweith et al., 2017). However, the fact that earwigs were raised under special conditions in this previous experiment - manipulation of the maternal presence and pathogens presence early in age - might shape their immunity differently and lead to contrasting results. Independent of this apparent discrepancy, the same lack of sex-specific level of hemocyte concentration in young adults has been reported in damselflies and attributed to their recent adult emergence, which induces numerous physiological change that are common to both sexes and could thus temporarily mask such an effect (Rolff, 2001). Conversely, the higher increase in hemocyte concentration observed in males compared to 
females can be explained by the different lifespan between the sexes: females must survive winter to take care of their offspring while males usually die over winter. Since investing into immunity can accelerate aging (Khan et al., 2017), it might be a strategy for females to increase their immunity as a protection against winter conditions but not up to a certain limit to preserve their body from cellular damage and thus extend their lifespan.

In group-living animals, the presence of conspecifics is traditionally known to increase the risks of pathogen exposure and therefore to shape investments into personal and collective defenses against pathogens (Cremer et al., 2007; McNeal et al., 2014; Meunier, 2015). Its corollary is that social isolation should also shape immune investments in group-living animals. Our results do not support this and show that being isolated over the entire reproductive period does not affect survival and immunity of male and female earwigs. These findings suggest that earwig adults either do not perceive the presence of a conspecific and/or do not consider that social isolation is a stress during the reproductive period, or that this stress does not affect their investment in immunity. In a previous study, adult earwigs have been shown to be less resistant against pathogen infections when suddenly isolated, but not when maintained in a constant isolation or in a group for one month (Kohlmeier et al., 2016). Hence, our results are likely to report a reduced stress of social isolation during the reproductive period.

To conclude, our study reveals that immune investment varies with the interactions between age, sex and mating status in earwigs, and that the effects of these factors depend on the considered immune parameter. In particular, we demonstrated that the concentration of circulating hemocytes was overall higher in earwig males compared to females, but only in old individuals. Similarly, there was an age-dependent increase of total-PO activity in virgin, but not in mated females. We also showed that the presence or absence of a conspecific during the reproductive period had no effect on adults' investment into the two measured 
immune functions. Altogether, these findings emphasize that a better understanding of how individuals invest into their protection against pathogen infections requires disentangling the independent and interactive effects of multiple factors on immune functions.

\section{Acknowledgments}

We thank Armin Joos for the technical assistance and Maximilian Körner for English improvement. FV was supported by the Humboldt foundation and JM by the German Science Foundation (DFG; ME4179/3-1). The authors declare no competing financial interests.

\section{References}

Armitage, S.A.O., Boomsma, J.J., 2010. The effects of age and social interactions on innate immunity in a leaf-cutting ant. J. Insect Physiol. 56, 780-787. doi:10.1016/j.jinsphys.2010.01.009

Armitage, S.A.O., Thompson, J.J.W., Rolff, J., Siva-Jothy, M.T., 2003. Examining costs of induced and constitutive immune investment in Tenebrio molitor. J. Evol. Biol. 16, 1038-1044. doi:10.1046/j.1420-9101.2003.00551.x

Cerenius, L., Lee, B.L., Söderhäll, K., 2008. The proPO-system: pros and cons for its role in invertebrate immunity. Trends Immunol. 29, 263-71. doi:10.1016/j.it.2008.02.009

Cerenius, L., Söderhäll, K., 2004. The prophenoloxidase-activating system in invertebrates. Immunol. Rev. 198, 116-26.

Cotter, S.C., Kilner, R.M., 2010. Sexual division of antibacterial resource defence in breeding burying beetles, Nicrophorus vespilloides. J. Anim. Ecol. 79, 35-43. doi:10.1111/j.13652656.2009.01593.x

Cotter, S.C., Littlefair, J.E., Grantham, P.J., Kilner, R.M., 2013. A direct physiological tradeoff between personal and social immunity. J. Anim. Ecol. 82, 846-853.

doi:10.1111/1365-2656.12047 
Cremer, S., Armitage, S.A.O., Schmid-Hempel, P., 2007. Social Immunity. Curr. Biol. 17, 693-702. doi:10.1016/j.cub.2007.06.008

Dubovskiy, I.M., Whitten, M.M.A., Kryukov, V.Y., Yaroslavtseva, O.N., Grizanova, E. V., Greig, C., Mukherjee, K., Vilcinskas, A., Mitkovets, P. V., Glupov, V. V., Butt, T.M., 2013. More than a colour change: insect melanism, disease resistance and fecundity.

Proc. R. Soc. B Biol. Sci. 280, 20130584-20130584. doi:10.1098/rspb.2013.0584

Evison, S.E.F., Gallagher, J.D., Thompson, J.J.W., Siva-Jothy, M.T., Armitage, S.A.O., 2017. Cuticular colour reflects underlying architecture and is affected by a limiting resource. J. Insect Physiol. 98, 7-13. doi:10.1016/j.jinsphys.2016.11.005

Fedorka, K.M., Copeland, E.K., Winterhalter, W.E., 2013a. Seasonality influences cuticle melanization and immune defense in a cricket: support for a temperature-dependent immune investment hypothesis in insects. J. Exp. Biol. 216, 4005-4010. doi:10.1242/jeb.091538

Fedorka, K.M., Lee, V., Winterhalter, W.E., 2013b. Thermal environment shapes cuticle melanism and melanin-based immunity in the ground cricket Allonemobius socius. Evol. Ecol. 27, 521-531. doi:10.1007/s10682-012-9620-0

Fedorka, K.M., Zuk, M., Mousseau, T.A., 2004. Immune suppression and the cost of reproduction in the ground cricket, Allonemobius socius. Evolution (N. Y). 58, 24782485. doi:10.1111/j.0014-3820.2004.tb00877.x

French, S.S., Johnston, G.I.H., Moore, M.C., 2007. Immune activity suppresses reproduction in food-limited female tree lizards Urosaurus ornatus. Funct. Ecol. 21, 1115-1122. doi:10.1111/j.1365-2435.2007.01311.x

González-Santoyo, I., Córdoba-Aguilar, A., 2012. Phenoloxidase : a key component of the insect immune system. Entomol. Exp. Appl. 142, 1-16. doi:10.1111/j.15707458.2011.01187.x 
Khan, I., Agashe, D., Rolff, J., 2017. Early-life inflammation, immune response and ageing. Proc. R. Soc. Lond. B 284, 20170125. doi:10.1098/rspb.2017.0125

Khan, I., Prakash, A., Agashe, D., 2016. Immunosenescence and the ability to survive bacterial infection in the red flour beetle Tribolium castaneum . J. Anim. Ecol. 85, 291301. doi:10.1111/1365-2656.12433

Koch, L.K., Meunier, J., 2014. Mother and offspring fitness in an insect with maternal care: phenotypic trade-offs between egg number, egg mass and egg care. BMC Evol. Biol. 14, 125. doi:10.1186/1471-2148-14-125

Kohlmeier, P., Dreyer, H., Meunier, J., 2015. PO-CALC: A novel tool to correct common inconsistencies in the measurement of phenoloxidase activity. J. Insect Physiol. 75, 8084. doi:10.1016/j.jinsphys.2015.02.015

Kohlmeier, P., Holländer, K., Meunier, J., 2016. Survival after pathogen exposure in groupliving insects: Don’t forget the stress of social isolation! J. Evol. Biol. 29, 1867-1872. doi:10.1111/jeb.12916

Kramer, J., Meunier, J., 2015. Maternal condition determines offspring behavior toward family members in the European earwig. Behav. Ecol. 0, 1-7. doi:10.1093/beheco/arv181

Kramer, J., Thesing, J., Meunier, J., 2015. Negative association between parental care and sibling cooperation in earwigs: a new perspective on the early evolution of family life? J. Evol. Biol. 28, 1299-1308. doi:10.1111/jeb.12655

Kurtz, J., Wiesner, A., Götz, P., Sauer, K.P., 2000. Gender differences and individual variation in the immune system of the scorpionfly Panorpa vulgaris (Insecta: Mecoptera). Dev. Comp. Immunol. 24, 1-12.

Lacoue-Labarthe, T., Bustamante, P., Hörlin, E., Luna-Acosta, A., Bado-Nilles, A., ThomasGuyon, H., 2009. Phenoloxidase activation in the embryo of the common cuttlefish Sepia 
officinalis and responses to the Ag and $\mathrm{Cu}$ exposure. Fish Shellfish Immunol. 27, 516521. doi:10.1016/j.fsi.2009.07.002

Lavine, M.D., Strand, M.R., 2002. Insect hemocytes and their role in immunity. Insect Biochem. Mol. Biol. 32, 1295-309.

Lawniczak, M.K.N., Barnes, A.I., Linklater, J.R., Boone, J.M., Wigby, S., Chapman, T., 2007. Mating and immunity in invertebrates. Trends Ecol. Evol. 22, 48-55. doi:10.1016/j.tree.2006.09.012

Mackenzie, D.K., Bussière, L.F., Tinsley, M.C., 2011. Senescence of the cellular immune response in Drosophila melanogaster. Exp. Gerontol. 46, 853-859.

Martin, L.B., Weil, Z.M., Nelson, R.J., 2008. Seasonal changes in vertebrate immune activity: mediation by physiological trade-offs. Philos. Trans. R. Soc. B Biol. Sci. 363, 321-339. doi:10.1098/rstb.2007.2142

McKean, K.A., Nunney, L., 2001. Increased sexual activity reduces male immune function in Drosophila melanogaster. Proc. Natl. Acad. Sci. 98, 7904-7909. doi:10.1073/pnas.131216398

McNeal, N., Scotti, M.A.L., Wardwell, J., Chandler, D.L., Bates, S.L., LaRocca, M., Trahanas, D.M., Grippo, A.J., 2014. Disruption of social bonds induces behavioral and physiological dysregulation in male and female prairie voles. Auton. Neurosci. Basic Clin. 180, 9-16. doi:10.1016/j.autneu.2013.10.001

Meunier, J., 2015. Social immunity and the evolution of group living in insects. Philos. Trans. R. Soc. London B Biol. Sci. 370, 20140102. doi:10.1098/rstb.2014.0102

Meunier, J., Wong, J.W.Y., Gomez, Y., Kuttler, S., Rollin, L., Stucki, D., Kölliker, M., 2012. One clutch or two clutches? Fitness correlates of coexisting alternative female lifehistories in the European earwig. Evol. Ecol. 26, 669-682. doi:10.1007/s 10682-011$9510-\mathrm{x}$ 
Møller, A.P., Merino, S., Brown, C.R., Robertson, R.J., 2001. Immune defense and host sociality: a comparative study of swallows and martins. Am. Nat. 158, 136-145. doi:10.1086/321308

Nappi, A.J., Christensen, B.M., 2005. Melanogenesis and associated cytotoxic reactions: applications to insect innate immunity. Insect Biochem. Mol. Biol. 35, 443-59. doi:10.1016/j.ibmb.2005.01.014

Nappi, A.J., Ottaviani, E., 2000. Cytotoxicity and cytotoxie molecules in invertebrates. BioEssays 22, 469-480.

Nelson, R.J., Demas, G.E., 1996. Seasonal Changes in Immune Function. Q. Rev. Biol. 71, $511-548$.

Park, Y., Kim, Y., Stanley, D., 2011. Cellular immunosenescence in adult male crickets, Gryllus assimilis. Arch. Insect Biochem. Physiol. 76, 185-194. doi:10.1002/arch.20394

Ramsden, S., Cheung, Y.Y., Seroude, L., 2008. Functional analysis of the Drosophila immune response during aging. Aging Cell 7, 225-36. doi:10.1111/j.14749726.2008.00370.x

Ratz, T., Kramer, J., Veuille, M., Meunier, J., 2016. The population determines whether and how life-history traits vary between reproductive events in an insect with maternal care. Oecologia 182, 443-452. doi:10.1007/s00442-016-3685-3

Rolff, J., 2002. Bateman's principle and immunity. Proc Biol Sci 269, 867-872. doi:10.1098/rspb.2002.1959

Rolff, J., 2001. Effects of age and gender on immune function of dragonflies (Odonata, Lestidae) from a wild population. Can. J. Zool. 79, 2176-2180. doi:10.1139/cjz-79-122176

Rolff, J., Siva-Jothy, M.T., 2002. Copulation corrupts immunity: A mechanism for a cost of mating in insects. Proc. Natl. Acad. Sci. 99, 9916-9918. doi:10.1073/pnas.152271999 
Schmid-Hempel, P., 2005. Evolutionary ecology of insect immune defenses. Annu. Rev. Entomol. 50, 529-51. doi:10.1146/annurev.ento.50.071803.130420

Schwarzenbach, G.A., Hosken, D.J., Ward, P.I., 2005. Sex and immunity in the yellow dung fly Scathophaga stercoraria. J. Evol. Biol. 18, 455-463. doi:10.1111/j.14209101.2004.00820.x

Selman, C., Blount, J.D., Nussey, D.H., Speakman, J.R., 2012. Oxidative damage, ageing, and life-history evolution: Where now? Trends Ecol. Evol. 27, 570-577. doi:10.1016/j.tree.2012.06.006

Sinclair, J. a., Lochmiller, R.L., 2000. The winter immunoenhancement hypothesis: associations among immunity, density, and survival in prairie vole (Microtus ochrogaster) populations. Can. J. Zool. 78, 254-264. doi:10.1139/cjz-78-2-254

Siva-Jothy, M.T., Moret, Y., Rolff, J., 2005. Insect Immunity : An Evolutionary Ecology Perspective. Adv. In Insect Phys. 32, 1-48. doi:10.1016/S0065-2806(05)32001-7

Stanley, D., 2012. Aging and immunosenescence in invertebrates. Isj 9, 102-109.

Stoehr, A.M., 2007. Inter- and intra-sexual variation in immune defence in the cabbage white butterfly, Pieris rapae L. (Lepidoptera : Pieridae). Ecol. Entomol. 32, 188-193.

Thesing, J., Kramer, J., Koch, L.K., Meunier, J., 2015. Short-term benefits, but transgenerational costs of maternal loss in an insect with facultative maternal care. Proc. R. Soc. B Biol. Sci. 282, 20151617. doi:10.1098/rspb.2015.1617

Trivers, R.L., 1972. Parental investment and sexual selection, in: Campbell, B. (Ed.), Sexual Selection and the Descent of Man, 1871-1971. Aldine Press, Chicago, pp. 136-175.

Vogelweith, F., Körner, M., Foitzik, S., Meunier, J., 2017. Age, pathogen exposure, but not maternal care shape offspring immunity in an insect with facultative family life. BMC Evol. Biol. 17, 69. doi:10.1186/s12862-017-0926-y

Wilson-Rich, N., Spivak, M., Fefferman, N.H., Starks, P.T., 2009. Genetic, individual, and 
group facilitation of disease resistance in insect societies. Annu. Rev. Entomol. 54, 405423. doi:10.1146/annurev.ento.53.103106.093301

Wilson, K., Cotter, S.C., 2008. Density-dependent prophylaxis in insects. Phenotypic Plast. insects Mech. consequences 44, 137-176.

Wilson, K., Knell, R., Boots, M., Koch-Osborne, J., 2003. Group-living and investment in immune response: an interspecific analysis. J. Anim. Ecol. 72, 133-143. doi:10.1046/j.1365-2656.2003.00680.x

Wilson, K., Reeson, A.F., 1998. Density-dependent prophylaxis: evidence from Lepidopterabaculovirus interactions? Ecol. Entomol. 23, 100-101.

Wilson, K., Thomas, M.B., Blanford, S., Doggett, M., Simpson, S.J., Moore, S.L., 2002. Coping with crowds: density-dependent disease resistance in desert locusts. Proc. Natl. Acad. Sci. U. S. A. 99, 5471-5475. doi:10.1073/pnas.082461999

Xu, Y.C., Yang, D.B., Wang, D.H., 2012. No evidence for a trade-off between reproductive investment and immunity in a rodent. PLoS One 7, 1-11. doi:10.1371/journal.pone.0037182 
Table 1. Effects of age, body size (eye distance), mating status, sex and social isolation on immune parameters in adults. Significant p-values are in bold. The interactions removed during model simplifications are not reported in this table (-).

\begin{tabular}{|c|c|c|c|c|c|c|c|c|}
\hline & \multicolumn{2}{|c|}{$\begin{array}{c}\text { Hemocyte } \\
\text { concentration }\end{array}$} & \multicolumn{2}{|c|}{$\begin{array}{c}\text { Total-PO } \\
\text { Activity (overall) }\end{array}$} & \multicolumn{2}{|c|}{$\begin{array}{l}\text { Total-PO activity } \\
\text { (Females only) }\end{array}$} & \multicolumn{2}{|c|}{$\begin{array}{l}\text { (d) Total-PO activity } \\
\text { (Males only) }\end{array}$} \\
\hline & Wald $\chi^{2}$ & $\mathrm{P}$ & Wald $\chi^{2}$ & $\mathrm{P}$ & Wald $\chi^{2}$ & $\mathrm{P}$ & Wald $\chi^{2}$ & $\mathrm{P}$ \\
\hline Age & 77.87 & $<0.0001$ & 108.95 & $<0.0001$ & $\mathbf{5 7 . 8 3}$ & $<0.0001$ & 48.64 & $<0.0001$ \\
\hline Eye distance & 1.47 & 0.224 & 1.08 & 0.299 & 0.15 & 0.670 & 1.18 & 0.277 \\
\hline Mating status (MS) & 0.06 & 0.803 & 1.48 & 0.224 & 0.09 & 0.756 & 2.89 & 0.089 \\
\hline Sex & 17.45 & $<0.0001$ & 3.77 & 0.052 & - & - & - & - \\
\hline Social isolation & 0.02 & 0.900 & 0.37 & 0.545 & 0.54 & 0.462 & 0.02 & 0.884 \\
\hline Age:MS & 0.70 & 0.400 & 3.60 & 0.058 & 14.27 & 0.0001 & 1.68 & 0.195 \\
\hline Age:Sex & 14.66 & 0.0001 & 0.69 & 0.407 & - & - & - & - \\
\hline Sex:MS & - & - & 0.65 & 0.420 & - & - & - & - \\
\hline Age:MS:Sex & - & - & 12.85 & 0.0003 & - & - & - & - \\
\hline
\end{tabular}




\section{Figure legends}

Figure 1. Overview of the experimental design for females. The same process has been used for males. The dashed circles represent isolated individuals, the dot-dashed circles represent the paired individuals, the circles with white background are virgin individuals and the circles with grey background are mated individuals.

Figure 2. Interactive effects of age and sex on hemocyte concentration (hemocytes/ $\mu$ l) in earwig adults. Light gray bars represent females and black bars represent the males. Sample sizes are provided at the bottom of each bar. Different letters indicate statistically significant differences $(\mathrm{p}<0.05)$.

Figure 3. Interactive effects of age and mating status on total-PO activity $\left(\mathrm{V}_{\max }\right.$ value $\left.\mathrm{x} 10^{3}\right)$ in (a) female and (b) male. White bars represent virgin adults and grey bars represent mated adults. Sample sizes are provided at the bottom of each bar. Different letters indicate statistically significant differences $(\mathrm{p}<0.05) .{ }^{* * *} \mathrm{p}<0.0001$

Figure 4. Effect of (a) mating status, (b) sex and (c) social isolation on the adult's survival rate over the experiment. Sample sizes are provided at the bottom of each bar. N.s. indicates non-significant differences $(\mathrm{p}>0.05)$. Note that survival was assessed at the end of the experiment, consequently there is not effect of the age. 


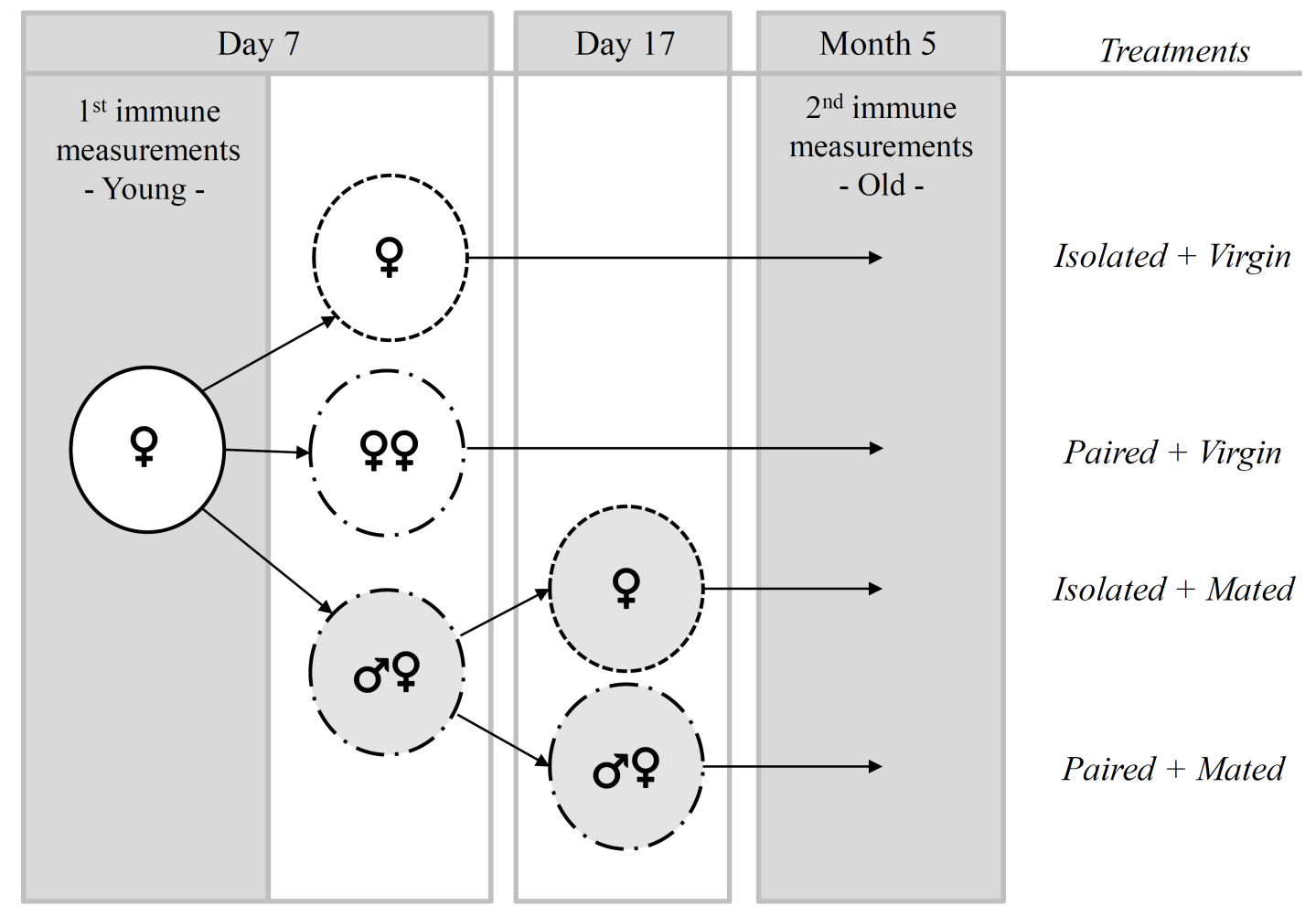

Figure 1 


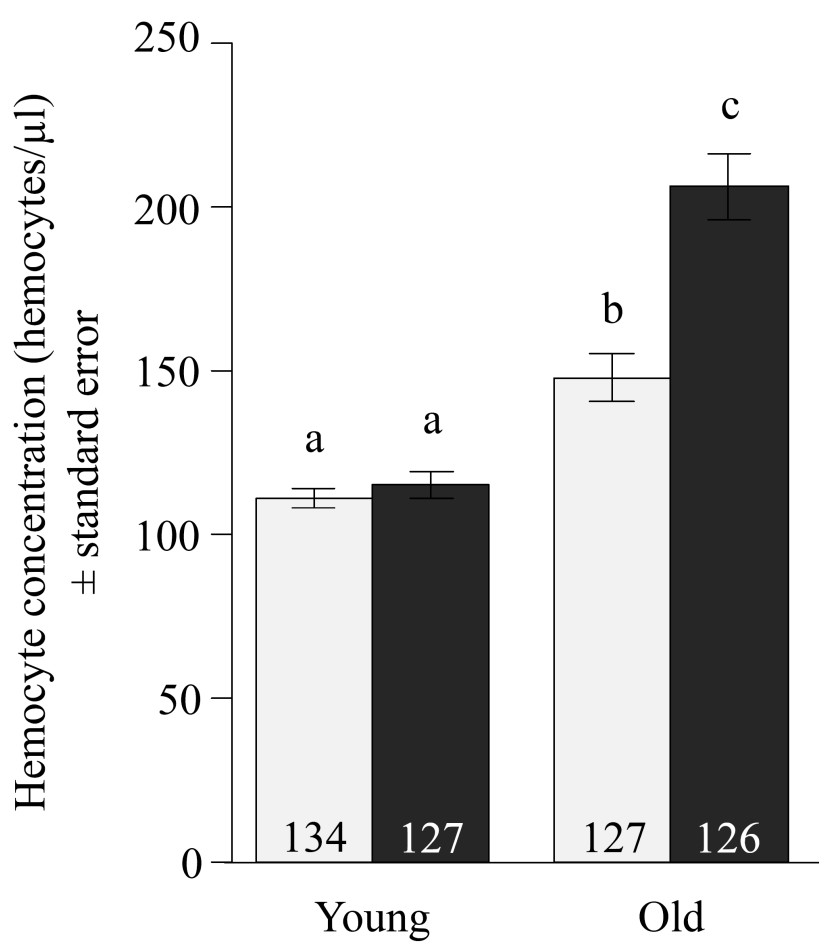

Age

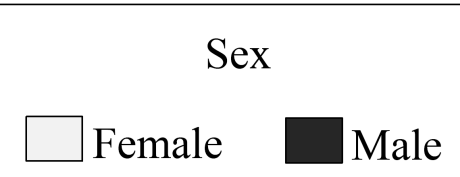

Figure 2 
(a)

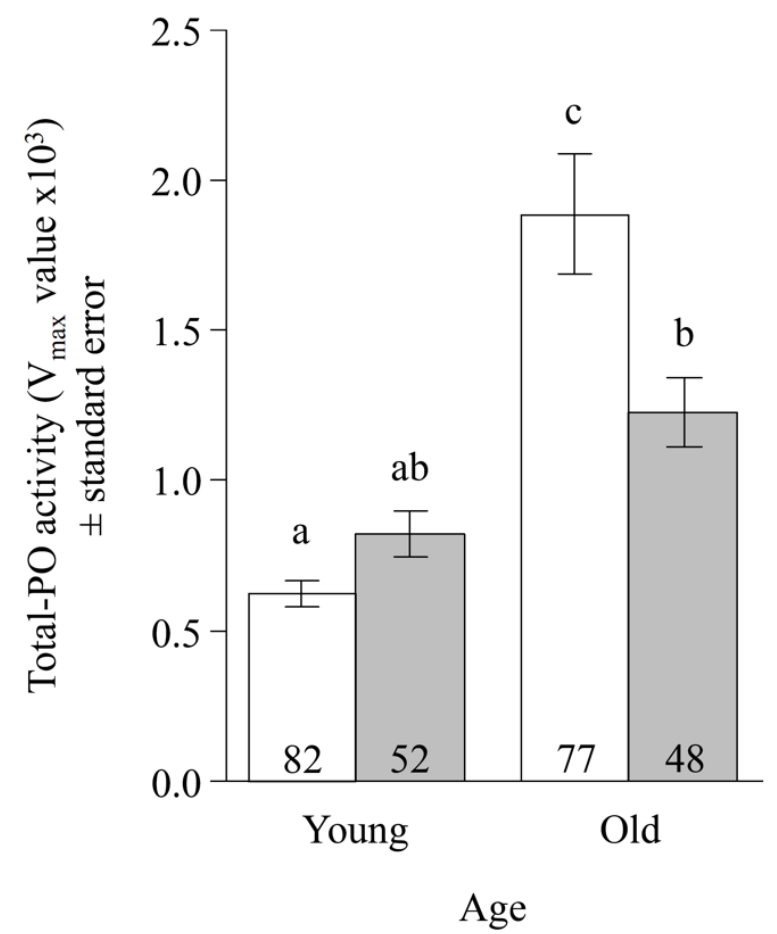

(b)

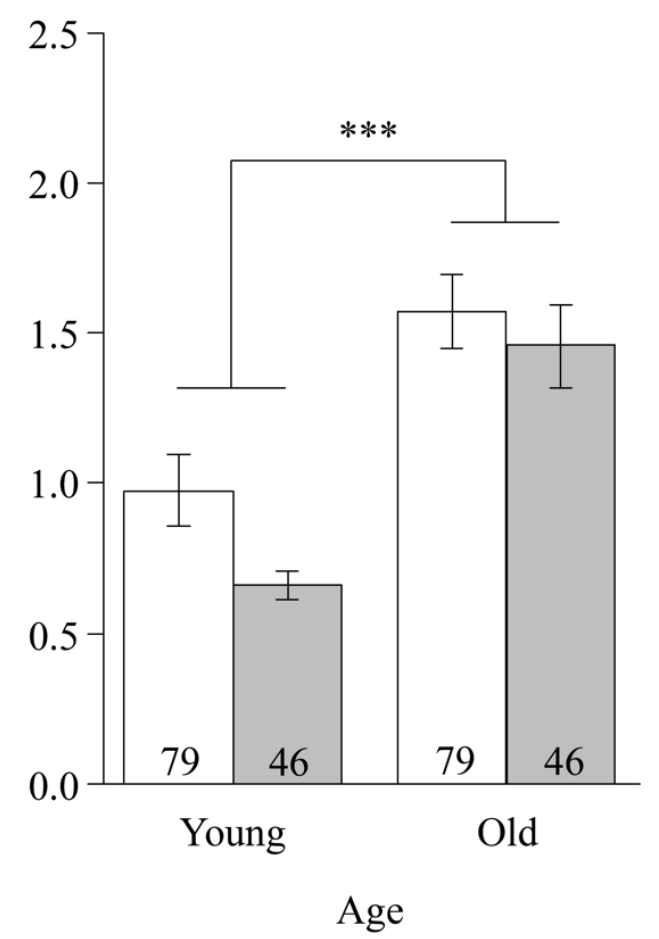

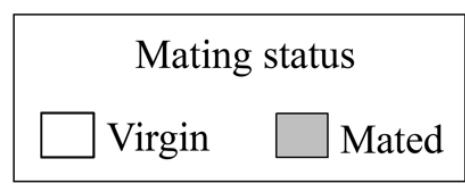

Figure 3 
(a)

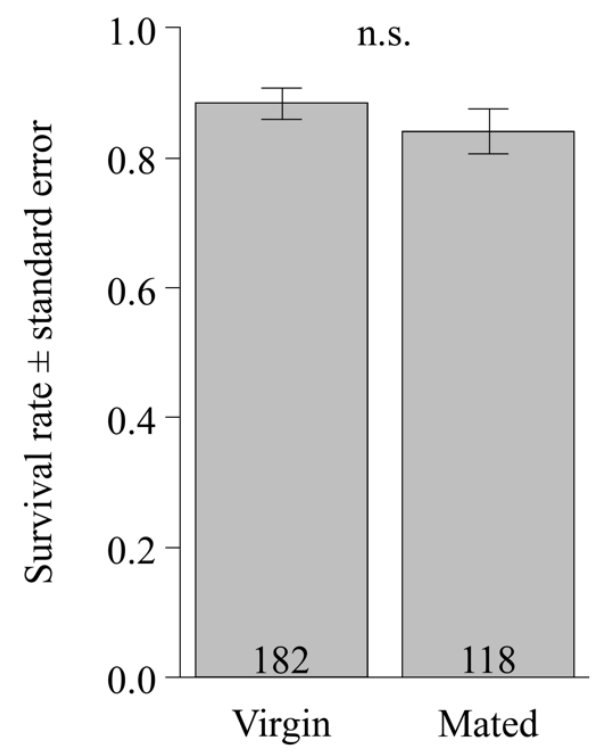

Mating status (b)

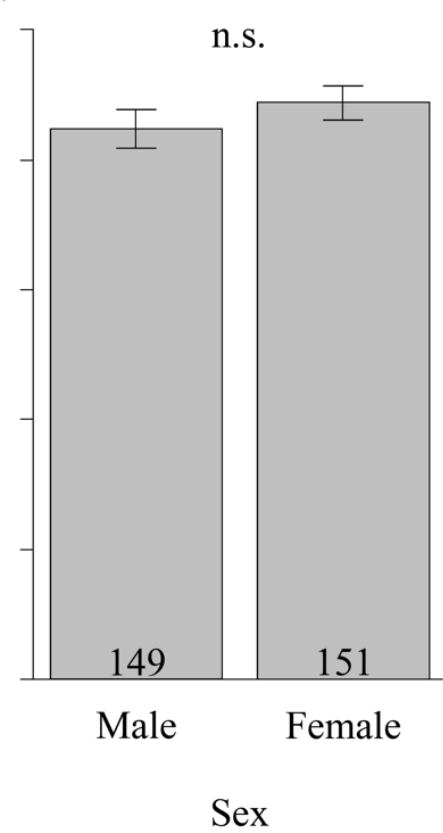

(c)

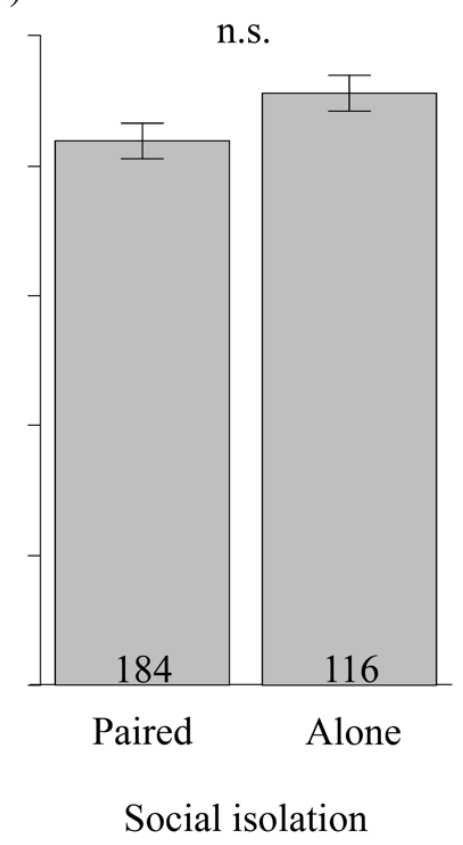

Figure 4 